University of Wollongong

Research Online

Faculty of Informatics - Papers (Archive)

Faculty of Engineering and Information

Sciences

2010

\title{
A feasibility of incorporating PDAs into problem-based learning approach to medical education: An overview
}

\author{
Rattiporn Luanrattana \\ University of Wollongong, r1631@uow.edu.au \\ Khin Than Win \\ University of Wollongong, win@uow.edu.au \\ John Fulcher \\ University of Wollongong, john@uow.edu.au
}

Follow this and additional works at: https://ro.uow.edu.au/infopapers

Part of the Physical Sciences and Mathematics Commons

\section{Recommended Citation}

Luanrattana, Rattiporn; Win, Khin Than; and Fulcher, John: A feasibility of incorporating PDAs into problem-based learning approach to medical education: An overview 2010.

https://ro.uow.edu.au/infopapers/3435 


\title{
A feasibility of incorporating PDAs into problem-based learning approach to medical education: An overview
}

\author{
Abstract \\ This paper explores the feasibility of incorporating personal digital assistants (PDAs) into problem-based \\ learning (PBL) approach in medical education. Method: Database searched was conducted by using \\ relevant keywords. From 1,317 relevant journal articles, 489 articles (37\%) are related to the use of PDAs \\ in medical settings, medical education and aspects regarding PDA use in both areas. The appropriate \\ materials were input into NVivo 7 for analysis. Results: Five PDA functionalities (clinical-log, reference, \\ personal information management, communication and special functions) and 8 factors (data security \\ and information privacy, interoperability, scalability and network connectivity, education and training, \\ technology comfort, electromagnetic interference, social acceptance, and maintenance and support) for \\ the incorporation of PDAs into PBL-medical curriculum were identified. Conclusion: A little is known \\ whether PDAs can be incorporate at the beginning of medical study in particular to a PBL-medical \\ curriculum at the University of Wollongong (UOW). Therefore the further study is to determine whether \\ PDAs, their functionalities and influence factors are feasible to deploy into medical education and how \\ possible they can be incorporated to medical education at the UOW.

\section{Disciplines} \\ Physical Sciences and Mathematics

\section{Publication Details} \\ Luanrattana, R., Win, K. Than. \& Fulcher, J. (2010). A feasibility of incorporating PDAs into problem-based \\ learning approach to medical education: An overview. 2010 IEEE 24th International Conference on \\ Advanced Information Networking and Applications Workshops (WAINA 2010) (pp. 997-1004). Perth: \\ IEEE.
}




\title{
A Feasibility of Incorporating PDAs into Problem- Based Learning Approach to Medical Education: An Overview
}

\author{
Rattiporn Luanrattana, Khin Than Win, John Fulcher \\ Faculty of Informatics, University of Wollongong, NSW, Australia, 2522 \\ rattipornLnr@au.edu, \{win, john\}@uow.edu.au
}

\begin{abstract}
This paper explores the feasibility of incorporating personal digital assistants (PDAs) into problem-based learning (PBL) approach in medical education. Method: Database searched was conducted by using relevant keywords. From 1,317 relevant journal articles, 489 articles $(37 \%)$ are related to the use of PDAs in medical settings, medical education and aspects regarding PDA use in both areas. The appropriate materials were input into NVivo 7 for analysis. Results: Five PDA functionalities (clinical-log, reference, personal information management, communication and special functions) and 8 factors (data security and information privacy, interoperability, scalability and network connectivity, education and training, technology comfort, electromagnetic interference, social acceptance, and maintenance and support) for the incorporation of PDAs into PBL-medical curriculum were identified. Conclusion: A little is known whether PDAs can be incorporate at the beginning of medical study in particular to a PBL-medical curriculum at the University of Wollongong (UOW). Therefore the further study is to determine whether PDAs, their functionalities and influence factors are feasible to deploy into medical education and how possible they can be incorporated to medical education at the UOW.
\end{abstract}

Keywords-personal digital assistants, PDAs, medical education, problem-based learning approach, $P B L$

\section{INTRODUCTION}

The feasibility study of incorporating personal digital assistants (PDAs) into problem-based learning (PBL) approach in medical education has been derived and formulated based on the literature reviews regarding the context of PBL, PDA use in general, healthcare and medical professions and in medical education. There are four major reasons why this study has been conducted at the Graduate School of Medicine (GSM), the University of Wollongong (UOW). PDAs have been used for various purposes and functionalities. PDA use depends on particular job. Therefore, there is an opportunity that a number of PDA functionalities can be applied and used in medical education.

A number of medical schools have already incorporated PDAs into medical education (e.g. George Washington University School of Medicine, Johns Hopkins School of Medicine, Thomas Jefferson Medical College, etc.) [1, 2]. PDAs have been used in medical education as a learning tool for delivering and facilitating medical studies, for example, tracking student progress, accessing clinical materials and resources, looking up lab results, using as an electronic organiser or communicating with others.

However, there is no comprehensive study of PDA use in medical education regarding technical, ethical, clinical and practical aspects. Therefore this study is conducted in relation to PDA functionalities and relevant aspects to consider for the incorporation of PDA devices into a PBL-medical curriculum.

In the US medical schools with traditional medical curricula, the use of PDAs focuses on internship and clerkship programs. In the UOW students start having clinical placements from year-1 and it are intended to use PDAs from this time onwards. The contributions of this paper are prospective PDA functionalities for the UOW PBL-medical curriculum and possible aspects to consider before incorporating PDAs into medical education.

\section{METHODS}

Various key terms (PDAs, handheld computers, handheld devices, medical professions, medical education, PBL, problem-based learning approach, case-based learning and functionality) were used to identify and search all studies related in PDAs, applications and relevant aspects in both medical professions and medical education from various databases. The journal article search was restricted to Englishlanguage articles that were published from 2000 to 2009.

The search strategy of using relevant keywords was used to gather al journal articles and studies related to PDA use in medical professions and medical education from the relevant databases (e.g. PubMed, Medline, ScienceDirect, Proquest, etc). The article selection process began by screening the article's title, abstract, keywords and full-text article that contained the related information. From 1,317 relevant journal articles, there were 489 articles (37\%) are related to the use of PDAs in medical settings, medical education and aspects regarding PDA use in both areas. The articles were loaded into Nvivo 7. The each article was extracted, coded and analysed in Nvivo with ten major themes, including PDA functionalities, data security and information privacy, interoperability and PDA platforms, scalability and network connectivity, education and training, technology comfort, electromagnetic interference (EI), social acceptance, maintenance and support, and other aspects. 


\section{RESULTS}

The results were categorized into two major categories, including prospective PDA functionalities for medical education, and various factors to be considered before incorporating PDAs into medical education in the following sections.

\section{A. Prospective PDA Functionalities for the PBL-medical Curriculum at UOW}

There are a number of PDA functionalities which can possibly be deployed into medical education. Such functionalities are generally categorised into five-major classes, namely electronic clinical-log, reference, communication, personal information management (PIM) and special functions in medical education. Details of each functionality are identified and discussed in the following sections.

1) Electronic clinical-log: Electronic clinical-log is a useful functionality for both students and medical faculty. Generally, a clinical-log has numerous advantages. Such advantages are beneficial for students, medical faculty and clinical preceptors in terms of self-assessment, monitoring students' clinical experiences, future curriculum evaluation and development, and future research in medical education [3, 4].

There are a number of reasons why an electronic clinical$\log$ is a must have functionality in medical education. Firstly, it facilitates students in recording their clinical skills and experiences anytime when having clinical encounters. It facilitates students to immediately record clinical experiences at patient bedside or while on wards. Electronic clinical-logs are an effective way to record clinical experience and encounters, as clinical-log data can be easily accessed and retrieved from a central database server. It allows students to identify their learning needs based on their clinical experiences and gaps on their learning. Secondly, an electronic clinical-log enables clinical supervisors, phase directors or medical faculty to monitor students' progress. Therefore medical faculty, clinical supervisors and phase-directors can have a close supervision of students' clinical competency while offsite. Finally, having a record of clinical experiences and reflections in a clinical-log enables the medical school to perform complex data analysis for research and curriculum development [4, 5].

Further, electronic clinical-logs can be developed and implemented using various methods, including creating spreadsheets, programming, developing clinical-log systems or web-based clinical-logs. Having a web-based clinical-log is another alternative approach which allows students to access either via PDA or computer. The advantage of a web-based clinical-log is that it provides flexibility of software implementation. This is because web-programming can be run and used with any PDA platform. Students, therefore, would have flexibility in selecting and using any PDA platform, which would accommodate other uses of PDAs besides a clinical-log function. Another advantage is reliability in term of systems maintenance and support.

\begin{tabular}{|c|c|c|c|c|}
\hline \multicolumn{5}{|c|}{ Reference Functionalities } \\
\hline \multicolumn{2}{|l|}{$\begin{array}{l}\text { E-References and } \\
\text { e-Textbooks }\end{array}$} & \multicolumn{2}{|c|}{ Pharmaceutical Databases } & Clinical Guidelines \\
\hline \multirow{3}{*}{\multicolumn{2}{|c|}{$\begin{array}{l}\text { ABG Pro } \\
\text { Five Minute Clinical Consultant } \\
\text { Franklin electronic publishers } \\
\text { Harrison's principles of medicine } \\
\text { Language translator } \\
\text { MD Consult } \\
\text { Medical calculator } \\
\text { Merck Manual } \\
\text { NCBI Bookshelf (collection of free online } \\
\text { books provided by the US National Centre of } \\
\text { Biotechnology Information) } \\
\text { Redbook } \\
\text { Skyscape } \\
\text { StatRef. (Medical science textbooks and other } \\
\text { resources) } \\
\text { Taylor and Francis online eBook library }\end{array}$}} & \multirow{3}{*}{\multicolumn{2}{|c|}{$\begin{array}{l}\text { A2ZDrugs } \\
\text { ABX guide } \\
\text { AHFS drug information } \\
\text { Alternative drugs } \\
\text { Australian medicine handbook } \\
\text { Australian prescription product guide } \\
\text { British pharmacopoeia } \\
\text { Clinical algorithms } \\
\text { Differential diagnoses } \\
\text { Drug dosage } \\
\text { Drug facts and comparisons } \\
\text { Drug interactions } \\
\text { ePocrate Rx } \\
\text { LexiDrugs } \\
\text { Medical rules databases } \\
\text { MIMS } \\
\text { Medline Plus (drugs, supplements and herbal information) } \\
\text { Pocket Pharmacopoeia } \\
\text { The Lothian Drugs Formulary }\end{array}$}} & $\begin{array}{l}\text { Clinical information guidelines } \\
\text { Clinical practice guidelines } \\
\text { Therapeutic guidelines }\end{array}$ \\
\hline & & & & Dictionaries \\
\hline & & & & $\begin{array}{l}\text { MEDLINE Plus (Medical } \\
\text { Dictionary) } \\
\text { On-line Medical Dictionary } \\
\text { Dictionary of Public Health }\end{array}$ \\
\hline Journal Informations & \multicolumn{2}{|c|}{ Disease Classification } & $\begin{array}{l}\text { Medical calculators, scores } \\
\text { and algorithms }\end{array}$ & $\begin{array}{l}\text { Encyclopaedias and } \\
\text { others }\end{array}$ \\
\hline $\begin{array}{l}\text { NCBI Journal search } \\
\text { List of journals indexed in index } \\
\text { Medicus }\end{array}$ & \multicolumn{2}{|c|}{$\begin{array}{l}\text { International Classification of } \\
\text { Disease }\end{array}$} & $\begin{array}{l}\text { Body Mass Index Calculator } \\
\text { Gl Bleed Complication Risk } \\
\text { Bradycardia Treatment Algorithm }\end{array}$ & $\begin{array}{l}\text { ADAM Medical Encyclopaedias } \\
\text { Medical directory }\end{array}$ \\
\hline
\end{tabular}

Figure 1. Prospective reference functionality

2) Reference functionality: Reference functionality would be a large part of PDA use in medical education. The reasons why reference is a compulsory PDA functionality is that, firstly, it provides immediate access to clinical resources. This would be beneficial for students in practicing and studying medicine in the clinical placements. Secondly, with immediate access to relevant resources and materials, students could enhance the development of clinical experiences and skills in relation to clinical decision making, decreasing medical errors and adverse events, clinical procedures, drug interactions, etc [6].

A number of reference software applications for PDAs has been used in both the medical professions and medical 
education. A certain range of reference applications, which have been identified through the literature reviews, are proposed as prospective reference functionality for medical education in a PBL context. These references are categorised into several groups (Figure 1).

In addition, the reference resources and materials recommended in this section are generally based on the literature and document reviews [7]. However, all reference functionality has yet to be evaluated by medical faculty and honorary clinical academics whether they are appropriate for medical education, in PBL-approach.

3) PIM functionality: According to the original function of PDAs, there are generally designed to be an electronic organiser, which comes with instant functions, for instance, address book, calendar and personal diary [8]. Therefore such functions are recommended for students to manage their schedules, reminders and school events, personal contacts with peers, medical academics and clinical supervisors.

4) Communication functionality: Communication is an important functionality, as students can use this function for downloading and uploading their clinical-logs to university servers, sending and receiving e-mails and looking-up clinical resources and materials online. Furthermore, the communication function can be used for socialise between students and their peers. The proposed communication functionalities are e-mail, Internet access, text-message, paging-service, internet telephony and mobile phone for any PDA phones $[9,10]$.

The communication functionality comprises two categories, namely asynchronous and synchronous communication. Asynchronous non-real time communication allows students to post their comments on blogs, podcasts, vodcasts, blikis, forum or 'wiki' $[11,12]$. Therefore asynchronous communication may take longer time to respond than other types of communication.

TABLE I. THE PROPOSED PDA APPLICATIONS FOR ASYNCHRONOUS AND SYNCHRONOUS COMMUNICATION FUNCTIONALITY

\begin{tabular}{|l|l|l|}
\hline \multicolumn{3}{|c|}{$\begin{array}{c}\text { PDA Applications for asynchronous and synchronous } \\
\text { communication functionalities }\end{array}$} \\
\hline \multicolumn{2}{|c|}{ Asynchronous Communication } & Synchronous Communication \\
\hline Blog & Forum & Text-chats \\
\hline Podcast & e-mail & Document exchange function \\
\hline Vodcast & Text-message & Voice communication \\
\hline Blikis & $\begin{array}{l}\text { Any non real-time } \\
\text { applications }\end{array}$ & Real-time conference tool \\
\hline Wiki & & \\
\hline
\end{tabular}

On the other hand, synchronous data communication could be implemented on PDAs. However, it is dependent on three factors, these being (i) network and Internet connectivity, (ii) speed of data transmission and (iii) memory capacity of PDAs. Proposed applications for synchronous communication for PDAs in medical education are text-chats, document exchange, voice communication and real-time conference tools [11, 12]. Table I summarises the proposed communication applications for both asynchronous and synchronous communication [11, 13].
5) Special functions in medical education: Special functions are the additional functionalities. These functions are the proposed PDA functionalities after incorporating PDAs into medical education for certain years. The idea of having special functions could possibly be designed and developed according to the requirements of medical school.

\section{B. Considerable Factors of Incorporating PDA into Medical Education}

The purpose of this section is to address potential concerns which may impact the incorporation of PDAs into medical education, these being data security and information privacy, interoperability, scalability and network connectivity, education and training, technology comfort, EI, social acceptance, maintenance and support and other aspects.

\section{1) Data security and information privacy}

a) Data security: The data security techniques can be categorised into two strategies. Firstly, the data security strategy is focused on the security of PDA functionalities, in particular clinical-log and communication functions. Secondly, the data security strategy emphasises data security of the PDA device itself, the so called "physical data security of PDA" $[14,15]$.

b) Information privacy: Information privacy is a concern for any sensitive data which is recorded using the clinical-log function. Policies, procedures and regulations regarding information privacy [16], particularly regarding patient's clinical information, should be introduced for students to follow and practice for their future profession. The key element is that any patient information being recorded, either on clinical-logs or elsewhere, should be recorded without any patient identifier, a information about patients must remain anonymous.

2) Interoperability and PDA Platforms: Interoperability of PDAs refers to the transferability of information among different platforms, devices, functionality and systems. There are three factors which may affect interoperability among systems and different PDA platforms, these being (i) structure of data, (ii) content of data, (iii) protocol and techniques for data transmission [13]. Interoperability in this study is essentially focuses on the interoperability of PDAs and other mobile devices (e.g. PDA phones, tabletPC, Smartphone and laptop computers), as well as the interoperability of reference software applications for medical education.

a) Interoperability of PDA functionality on both PDAs and other mobile devices: Various authoring tools for developing a particular PDA functionality for medical education are recommended in order to support the interoperability of PDAs and other mobile technologies, including wireless application protocol (WAP) applications on mobile phones, second and third generation mobile phone, smartphones, tablet PC and laptop computers.

Therefore the use of Java 2 Platform Micro Edition (J2ME), and JavaScript are recommended as a tool for developing certain PDA functionalities in medical education, particularly when students use different PDA platforms or other mobile 
technologies. The incorporation of PDAs and their applications are also dependent on connection mechanisms, courseware import and export, and learning record buffering.

b) Interoperability of reference software applications in reference functionality: There are a number of software applications, which are available in both PalmOS and PocketPC. These are medical link resources, medical databases, medical calculators, drug guidelines, patient information, medical textbooks and journals and evidencebased medicine (EBM) applications. On the other hand, there are a certain range of software application, which can be used either on PalmOS or PocketPC. Therefore, the primary consideration of which reference software applications are suitable for medical education or whether each application has interoperability among different platforms is directly dependent on the final decision of the medical school and clinical academics.

c) PDA Platforms: The selection of PDA platform may impact on the interoperability of software applications. Two major PDA platforms were identified based on the literature reviews [7]. However, the selection of which PDA platform to use in medical education is dependent on various factors, such as (i) requirements of the medical school regarding PDA use, (ii) interoperability of PDAs with the university network and off-campus networks, (iii) the availability of medical software applications, (iv) maintenance and support of clinical-logs and other functions.

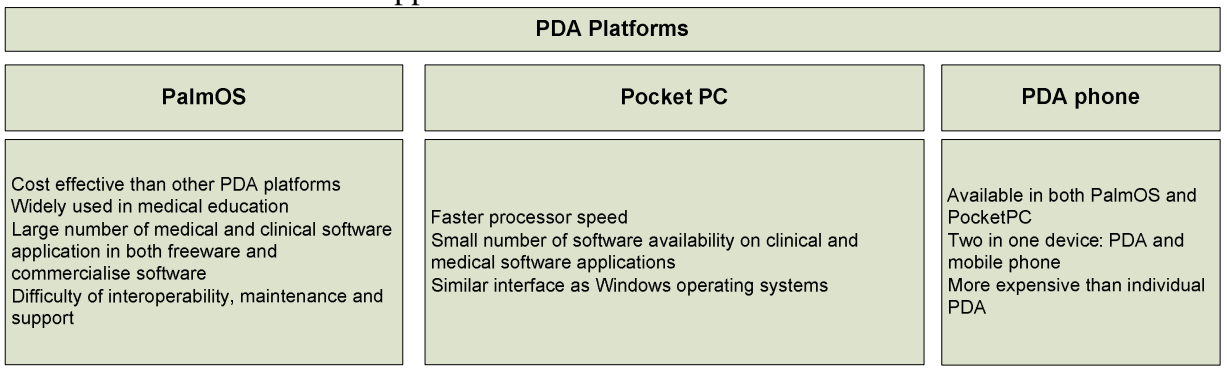

Figure 2. A comparison between three different PDA platforms

There are two reasons why Palm PDAs are being used in many medical schools (Figure 2). Firstly, Palm is more cost effective than other PDA platforms. Secondly, there are a number of reference software applications and medical resources available for PalmOS. Such software applications are available in both freeware and commercial software form. PalmOS has some weaker drawbacks regarding interoperability, maintenance and support [6].

d) Software availability: The selection of PDA platform is directly affected by the availability of software applications, in particular the reference functionality. As mentioned, PalmOS has greater medical reference software applications than PocketPC [17].

3) Scalability and network connectivity: Scalability is a vital factor for the medical school to consider for the future use of software applications and the increment of medical students in each year. Special software applications, such as clinical-log, objective structured clinical examination (OSCE) and classroom polling systems should be designed and developed for future expansion with respect to the increasing number of students in each academic year.

Network connectivity and data synchronisation. The data synchronisation is varied in different network connectivity. According to the literature reviews, data can be synchronised to database server(s) using six different techniques, namely HotSync via PDA cradle, Infrared, Bluetooth, remote access via the Internet, Wi-Fi and virtual private network (VPN) [18, 19]. The purpose of data synchronisation is threefold, more specifically (i) to backup data between PDAs to students' desktop computer; (ii) to install software applications onto
PDAs and; (iii) to transfer data to the database server on the campus network.

4) Education and training: Providing sufficient education and training regarding PDA use in medical education would impact the adoption of PDAs. Therefore, such education and training should be available for students, medical faculty and clinical academics. However, the the purposes of using PDA in medical education while offsite should be informed to the community especially in hospitals and clinical placements, in order to decrease bias, especially from patients, healthcare and medical professional.

5) Technology comfort: Technology comfort of PDA users is generally associated with other factors, including providing sufficient education and training on PDA use and importantly having relevant maintenance and support for PDA users if necessary. Being comfortable with PDA use would give rise to competency in using PDAs, which would impact on effectiveness and efficiency in learning and practicing medicine [20, 21].

6) EI: Wireless technologies which are based on radio frequency technology can be susceptible to EI, and can take the form of interference to the wireless link or medical devices. Cellular technology has been shown to cause EI [23].

Wireless technologies use burst rather than constant transmission, for instance, the IEEE 802.11b wireless Ethernet standard and Bluetooth operate at much lower power levels than cellular technology. Further, wireless technologies also use various methods for data transmission, including frequency hopping spread spectrum (FHSS) or direct sequence spread spectrum (DSSS), which would lower the risk of EI. On the 
other hand, Infrared communication does not carry any risk of interference, but it has a narrow bandwidth and reduces range. Using PDAs with wireless connectivity does not have any EI with medical equipment including pacemakers $[10,14]$.

7) Social acceptance: Social acceptance may influence PDA use particularly in the hospitals and clinical placements, even assuming education and training of community. PDA use could be restricted in certain situations, especially during clinical attachments as using PDAs during clinical contacts could interfere the patients [24, 25].

8) Maintenance and support: Maintenance and support should be considered. The medical school should consider what type of maintenance and support is appropriate for PDAs in order to support the ease of using devices in medical education and be reachable for any user when needed. Further, such maintenance and support could include hardware, software, network connectivity [24, 26, 27]. Nevertheless, various ways of providing maintenance and support for PDA users, for instance, helpdesk, e-mail support, live chat with technical staff, web-information, FAQ, user tips, peers, troubleshooting page, etc [27, 28].

\section{DISCUSSION}

The study can be used as a future guide for deploying PDAs into medical education, which aims to facilitate and enhance the quality of learning in a medical education context. PDA functionalities and factors to be considered for the incorporation of PDAs have identified. In addition, other aspects are necessary to be further explored, these being education and training, financial implications and attitudes of medical faculty and clinicians regarding PDA use in medical education. The detail of each aspect is discussed in the following sections. Figure 3 provides the basic foundations of this study.

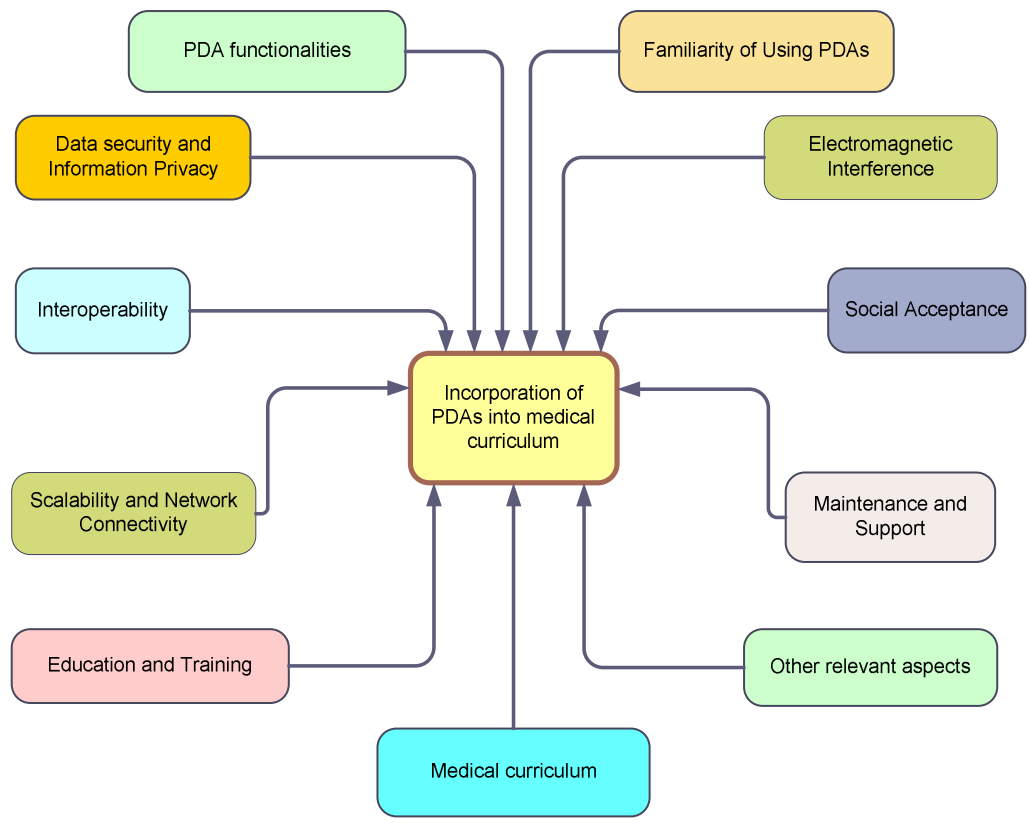

Figure 3. Factors to be considered for the incorporatio of PDAs into a PBL-medical curriculum at UOW

The factors to be considered for the incorporation of PDAs into PBL-medical curriculum at the UOW incorporated:

- $\quad$ an analytical view of prospective PDA functionalities and possible technical and practical aspects that would influence the incorporation of PDAs into a PBLmedical curriculum at UOW;

- a solid and practical literature regarding PDAs, PDA use in general, medical professions and medical education, and a review of various medical curricula in different medical schools elsewhere.

The important aspect of this study is to demonstrate the association between incorporating PDAs into medical education and other components, including (i) medical curriculum, (ii) PDA functionalities and (iii) other relevant aspects that would affect the deployment of PDA technology into medical education.

According to Figure 3, there are a number of considerable factors for incorporating PDAs into medical education. To conclude, there are three important factors of this study, which would possibly have a great impact to other factors. Firstly, the significant key factor of incorporating PDAs into medical education is PDA functionalities. Once the prospective PDA functionalities have been identified, then the appropriate PDA platforms and required software applications can be determined based on the medical school's requirements. The reason why PDA functionalities must be the first element for the medical school to consider is that any potential PDA functionality would affect the choice of both reference software applications and PDA platforms. Therefore, 
- the prospective PDA functionalities could be influenced by the requirements of medical school and the available software applications in the market. For instance, the possible special functionalities, which are useful for a PBL-medical curriculum at the UOW, may include classroom polling systems, teaching and interactive evaluation, evaluation of medical training, monitoring students' clinical experiences, data collection function for medical research, tracking or accessing medical images. These software applications and detail of special functions in medical education, in particular PBL-approach are to be identified, validated and explored for the possibility and appropriateness with the medical faculty and honorary clinical academics of the university;

- the prospective PDA functionalities would influence a selection of PDA platforms and software applications.

Secondly, medical curriculum is also an important factor, which would impact on the incorporation of PDAs into medical education. It is important to understand the context of medical curriculum in order to best utilise PDA technology in a learning context. If the incorporation of PDAs into medical curriculum could be tailor-made for particular needs then it would be suitable.

Thirdly, other important aspects include data security and information privacy, interoperability, scalability, education and training, technology comfort, EI, social acceptance, and maintenance and support.

Data security and information privacy. In order to ensure the security of PDA functionality in particular clinical-log, it is necessary to ensure that only authorised users can access their clinical-log either via PDAs or using other pervasive devices. Numerous data security procedures are available for both clinical-log and communication functions, including authentication methods using username and password protection, data encryption methods when sending information over the network, digital signatures, security over a wireless network, and using wired equivalent privacy (WEP) or Wi-Fi protected access (WPA). Generally, the simplest wireless network security for PDA devices is authentication methods and WPA.

Physical data security of PDA devices. The security of the physical device is also important. In order to protect personal data and sensitive data in case of PDA loss, it is recommended for the users to set and save their username and password protection which could prevent a security risk.

In terms of information privacy, the Health Records and Information Privacy Act 2002 (HRIPA) safeguards the privacy of health information. HRIPA governs organizations that handle any type of health information. HRIPA is concerned about data collection, storage, access, data accuracy, disclosure, data identifiers and anonymity, data transmission and linkage, and data authorisation.

The PDA functionality which directly deals with patient information, is the clinical-log function. Therefore the design of data field in this function must omit the data field for recording of any personal information that can identify who the patient is. However, the record of patient information, clinical experiences and personal reflections cannot be controlled if recorded elsewhere. Therefore students should strictly follow professional ethics and conduct on protecting and safeguarding patient information and the privacy of any individual patient.

Interoperability. The use of mobile technology is not only restricted with PDA devices and choices of operating systems. Now, it is possible that different students may use different mobile devices besides PDAs for accessing online clinicallogs. While one group of students may use PDA device, another group may use WAP applications on PDA phone to access and record their clinical-logs. Moreover, students may also use PC for recording their clinical-log information. These are possible scenario which may occur when it comes into daily activity.

In addition, reference software applications and relevant materials are generally available in both PalmOS and PocketPC. It is possible for medical schools to provide such resources in either PDA platform or both. However, in the case of using Smartphones for accessing reference materials, a problem regarding the availability of reference software application could arise.

Nevertheless developing any particular PDA system in medical education for both PalmOS and PocketPC is feasible. The important concern is to ensure that the systems are capable of network connectivity to PDA server as well as data security for different PDA platforms. Having systems which supports both PDA operating systems provides flexibility in selecting PDA devices based on user preference. However, the medical software applications must be provided for both platforms, which may increase the software purchase cost.

Scalability. For future expansion of network scalability, it is possible to linearly scale the database server to have an unlimited number of identical servers in a cluster represented only by one Internet protocol (IP) address on the network. However the potential number of medical students each year varies in each medical school, for instance, the GSM expects to have no more than 84 students per academic year (including 72-domestic and 12-international students).

Network connectivity. While on-campus, students are able to synchronise data via a PDA cradle (HotSync) or wireless (Wi-Fi) access via the campus network. It is recommended that HotSync spots should be provided for students to synchronise data back to the server as not every PDA has Wi-Fi access. HotSync spots should be available at several locations within the university, for instance, in the library, computer laboratory and medical school student lounge. As a result, students could synchronise data to the database server via the campusnetwork. On the one hand, students can synchronise data from elsewhere if they can log-on to the campus-network. The current standard Wi-Fi connections (wireless local area network or wireless LAN) for PDAs are IEEE 802.11a and IEEE $802.11 \mathrm{~b}$, with transmission speeds of 11 and $56 \mathrm{MB}$ per second, respectively. The implementation cost of wireless network connection is inexpensive and convenient for students to transfer and access data. Sending or exchanging data from 
peers-to-peers can be simply done by Infrared and Bluetooth, via Private Area Network (PAN) data transmission.

Alternatively, off-campus data transmission and synchronisation can be done by remote accessing over the Internet, Wi-Fi and VPN. However the implementation cost of VPN is quite high. VPN, which is one type of network connectivity for data transmission and synchronisation, is generally used in a small number of medical schools, for instance, Stanford University School of Medicine. Data exchange at the point of care service in clinical settings can be done via Infrared and Bluetooth connection.

Further considerations are the possible data synchronisation and network connectivity for on- and off-campus environments. Such data synchronisation and network connectivity are reasonable in terms of implementation, maintenance and support aspects.

On-Campus wireless network connectivity. On-campus wireless network connectivity is categorised into two major areas, namely inside and outside buildings. For inside buildings, the wireless network connection standard is IEEE802.11a (54 mb) and IEEE802.11b (11 mb). On the other hand, the wireless network connection standard for outside buildings is IEEE802.11b $(11 \mathrm{mb})$. Generally, any student with an active university e-mail account is eligible to gain wireless access to the on-campus environment.

Off-campus network connectivity. The proposed network connectivity for off-campus environments can be categorised into three major sources, these being Wi-Fi network connectivity, VPN and Internet connectivity via telecommunication companies.

TABLE II. CONSIDERABLE FACTORS BEFORE ESTABLISHING WIRELESS NETWORK CONNECTIVITY FOR OFF-CAMPUS NETWORK

\begin{tabular}{|l|l|}
\hline \multicolumn{1}{|c|}{$\begin{array}{c}\text { Considerable factors for wireless network connectivity for off- } \\
\text { campus environments }\end{array}$} \\
\hline $\begin{array}{l}\text { Network security and standard of } \\
\text { HRIP Acts }\end{array}$ & Outdoor applications \\
\hline $\begin{array}{l}\text { Site planning based on desired } \\
\text { network coverage and } \\
\text { electromagnetic interference }\end{array}$ & Mesh \\
\hline Software availability & Hotspot capabilities \\
\hline Required bandwidth & $\begin{array}{l}\text { Maintenance and support, } \\
\text { troubleshooting and daily } \\
\text { management }\end{array}$ \\
\hline Scalability & $\begin{array}{l}\text { Roaming capabilities from one } \\
\text { location to other locations (e.g. } \\
\text { between campus and clinical } \\
\text { setting) }\end{array}$ \\
\hline Quality of service & Support for other technologies \\
\hline Location requirements & $\begin{array}{l}\text { Minimal disruption in other areas } \\
\text { during installation }\end{array}$ \\
\hline
\end{tabular}

Firstly, Wi-Fi network connectivity is generally available in clinical placements, hospitals and general practice. However, using wireless Internet via the available networks in such locations is dependent on the agreement between the medical school and the former. Table II represents a number factors to be considered before establishing wireless network connectivity for off-campus environments. Secondly, while VPN is possible, it is not being considered by the medical school and university for future development and implementation due its high cost. Finally, having the Internet connection via PDA phone or Smartphones is also possible for students, especially while offsite in rural settings and remote areas. However, the cost of Internet connection via PDA phones and Smartphones is still expensive.

Education and training. The purposes of having education and training on PDAs in medical education are threefold. The first purpose is to inform learners, educators and the community regarding PDA use and how devices can enhance student in learning medicine. Especially, being well informed regarding PDA use in hospital and clinical placements could reduce bias from patients in the community. The second purpose is to provide education and training for medical educators (e.g. medical faculty and clinical academics) on how PDAs can facilitate them in teaching medicine either classroom or clinical environments. The final purpose is to provide education and training for students regarding PDA use, in particular how they can facilitate students in learning medicine and enhance their clinical skills while offsite.

EI. Using PDAs in hospital environments is recommended but wireless data transmission can be done in other area beside patients' wards, and keep distance from the medical devices. However the use of PDAs in clinical settings should be based on the policy and regulation of individual hospitals.

However, other aspects to consider before incorporating PDAs to medical education include organisational support from relevant parties, resource and financial implications, and other mobile technology options besides PDA devices. This feasibility study can be used as a general tool for systematically specify and identify a range of relevant aspects in the contexts being studied. The study would assist in setting the priority of each relevant aspect to be considered for the incorporation of PDAs into medical curriculum. Finally, this study facilitates the researcher in evaluating and identifying the outcomes whether the incorporation of PDAs into medical education in particular the UOW PBL-medical curriculum is feasible.

\section{CONCLUSION}

PDAs have been incorporated into the medical education elsewhere during pre-clinical or clerkship year. A little is known whether PDAs can be incorporated at the beginning of medical study in particular to a PBL-medical curriculum at the UOW. Therefore the further study is to determine whether the use of PDAs are feasible to deploy into a PBL-medical education at the UOW and how possible that PDAs can be deployed into medical education.

\section{ACKNOWLEDGMENT}

The authors would like to acknowledge all interview participants and gratefully acknowledge all assistance of Prof. Don Iverson and Prof. Patrick Crookes, and Assumption University for scholarship support.

\section{REFERENCES}

[1] P. Wilson, R. Billingsley, and L. Pellegrino, "PDA power at the bedside," Medical Reference Services Quarterly, vol. 24, pp. 1-7, 2005. 
[2] A.E. Carroll and D.A. Christakis, "Paediatricians' Use of and Attitudes About Personal Digital Assistants," Pediatrics, vol. 113, pp. 238-242, 2004.

[3] C.L. Bardes, S. Wenderoth, R. Lemise, P. Ortañez, and C. StoreyJohnson, "Specifying Student-Patient Encounters, Web-Based Case Logs, and Meeting Standards of the Liaison Committee on Medical Education," Academic Medicine, vol. 80, pp.11271132, 2005.

[4] C.J. Bertling, D.E. Simpson, A.M. Hayes, D. Torre, D.L. Brown, and D.B. Schubot, "Personal Digital Assistants Herald New Approaches to Teaching and Evaluation in Medical Education," Wisconsin Medical Journal, vol. 102, pp.45-50, 2003.

[5] A.M. Autry, D.E. Simpson, D.S.A. Bragg, L.N. Meurer, V.M. Barnabei, S.S. Green, C. Bertling, and B. Fisher, "Personal digital assistant for "real time" assessment of women's health in the clinical years," American Journal of Obstetrics and Gynecology, vol. 187, pp. 19-21, 2002.

[6] S. Holubar and L. Harvey-Banchik, "A Review of the Use of Handheld Computers in Medical Nutrition," Nutrition in Clinical Practice, vol. 22, pp.428-435, 2007.

[7] R. Luanrattana, K.T. Win, and J. Fulcher, "Use of Personal Digital Assistants (PDAs) in Medical Education," presented at CBMS '07. Twentieth IEEE International Symposium on Computer-Based Medical Systems, 2007. , Maribor, Slovenia, 2007.

[8] D.F. Criswell and M.L. Parchman, "Handheld Computer Use in U.S. Family Practice Residency Programs," Journal of American Medical Informatics Association, vol. 9, pp. 80-86, 2002.

[9] J.M. Sargeant, "Medical education for rural areas: Opportunities and challenges for information and communications technologies," Journal of Postgraduate Medicine, vol. 51, pp.301-307, 2005.

[10] B. Lin and J.A. Vassar, "Mobile healthcare computing devices for enterprise-wide patient data delivery," International Journal for Mobile Communication, vol. 2, pp. 343-353, 2004.

[11] S.T. Konstantinidis and P.D. Bamidis, "E-learning environments in medical education: How pervasive computing can influence the educational process," vol. 2008. Thessaloniki: Laboratory of Medical Informatics, Medical School, Aristotle University of Thessaloniki, 2007.

[12] A.P. Choules, "The use of elearning in medical education: a review of the current situation," Postgraduate Medical Journal vol. 83, pp.212-216, 2007.

[13] T. Read, F. Verdejo, and B. Barros, "Incorporating interoperability into a distributed eLearning system," 2007, pp. pp.1-4.

[14] P. Turner, G. Milne, M. Kubitscheck, I. Penman, and S. Turner, "Implementing a wireless network of PDAs in a hospital setting," Personal and Ubiquitous Computing. , vol. 9, pp. 209217, 2005.
[15] A. Miller, "PDA security concerns," Network Security, vol. 2004, pp. 8-10, 2004.

[16] D.J. Mole, C. Fox, and G. Napolitano, "Electronic Patient Data Confidentiality Practices Among Surgical Trainees: Questionnaire Study," Annals of The Royal College of Surgeons of England, vol. 88, pp.550-553, 2006.

[17] J.A. Lewis and C.O. Sommers, "Personal Data Assistants: Using New Technology to Enhance Nursing Practice," The American Journal of Maternal/Child Nursing, vol. 28, pp.66-73, 2003.

[18] R. Want and G. Borriello, "Survey on information appliances," IEEE Computer Graphics and Applications, vol. 20, pp.24-31, 2000.

[19] F. Hoffmann, J. Scott, M. Addlesee, G. Mapp, and A. Hopper, "Data transport on the networked surface," presented at 26th Annual IEEE Conference on Local Computer Networks, 2001. Proceedings. LCN 2001 Tampa, Florida, 2001.

[20] A. Kho, L.E. Henderson, D.D. Dressler, and S. Kripalani, "Use of Handheld Computers in Medical Education. A Systematic Review," Journal of General Internal Medicine, vol. 21, pp.531537, 2006.

[21] I. Scott, C. Wilson, and M. Gowans, "Are Personal Digital Assistants an Acceptable Incentive for Rural Community-based Preceptors?," Medical Informatics, vol. 37, pp.727-733, 2005.

[22] B.L. Seago, J.B. Schlesinger, and C.L. Hampton, "Using a decade of data on medical student computer literacy for strategic planning," Journal of Medical Library Association, vol. 90, pp.202-209, 2002.

[23] R.P. Jones and D.H. Conway, "The effect of electromagnetic interference from mobile communication on the performance of intensive care ventilators," European Journal of Anaesthesiology, vol. 22, pp.578-583, 2005.

[24] Y.-C. Lu, Y. Xiao, A. Sears, and J.A. Jacko, "A review and a framework of handheld computer adoption in healthcare," International Journal of Medical Informatics vol. 74, pp.409-422, 2005.

[25] S.E. Lapinsky, "Mobile computing in critical care," Journal of critical care vol. 22, pp.41-44, 2007.

[26] A.S. Menon, S. Moffett, M. Enriquez, M.M. Martinez, P. Dev, and T. Grappone, "Audience Response Made Easy: Using Personal Digital Assistants as a Classroom Polling Tool," Journal of American Medical Informatics Association, vol. 11, pp. 217-220, 2004.

[27] D. Topps, R. Thomas, and R. Crutcher, "Introducing Personal Digital Assistants to Family Physician Teachers," Medical Informatics, vol. 35, pp.55-59, 2003.

[28] S. Bakken, S.S. Cook, L. Curtis, M. Soupios, and C. Curran, "Informatics Competencies Pre- and Post-Implementation of a Palm-based Student Clinical Log and Informatics for Evidencebased Practice Curriculum," presented at American Medical Informatics Association Annual Symposium, 2003. 